\title{
管 \\ ENSINO DOS ESPORTES COLETIVOS NA EDUCAÇÃO FÍSICA ESCOLAR: UMA REVISÃO SISTEMÁTICA DA PRODUÇÃ̃O BRASILEIRA ${ }^{1}$
}

\section{TEACHING OF COLLECTIVE SPORTS IN SCHOOL PHYSICAL EDUCATION: A SYSTEMATIC REVIEW IN BRAZILIAN PRODUCTION}

\author{
ENSEÑANZA DE LOS DEPORTES COLECTIVOS EN LA EDUCACIÓN FÍSICA \\ ESCOLAR: UNA REVISIÓN SISTEMÁTICA EN LA PRODUCCIÓN BRASILEÑA
}

Gilberto Feitosa da Silva² Diego Luz Moura ${ }^{3}$

\begin{abstract}
Resumo: O esporte é um dos conteúdos mais tradicionais da educação física escolar, sendo utilizado por muitos professores com ênfase no ensino das habilidades motoras e dos gestos técnicos. Todavia, estudos reconhecem a importância desse conteúdo para além da sua prática, priorizando os valores e princípios educacionais. O objetivo do artigo foi analisar as produções acadêmicas sobre o ensino dos esportes coletivos na educação física escolar. A metodologia utilizada foi a revisão sistemática, buscando as publicações em oito revistas no período de 2006 a 2016. Foram analisados 26 estudos. Constatou-se que a baixa produção acadêmica e, consequentemente, as poucas propostas de intervenção podem ser alguns dos motivos das críticas que muitos autores fazem ao esporte. Apontamos a necessidade de mais estudos que auxiliem a prática pedagógica do professor, buscando compreender o cotidiano escolar e apresentando possibilidades para superar os dilemas presentes no ensino dos esportes na educação física escolar.
\end{abstract}

Palavras-chave: Educação. Ensino. Esportes coletivos. Educação física escolar.

\begin{abstract}
Sport is one of the most frequent indexes of School Physical Education, being used by many teachers with emphasis in the teaching of motor and gestural skills. However, students recognize their importance in this regard beyond their practice, prioritizing educational values and principles. The paper of the article was analyzed as academic production on the teaching of sports. Overall methodology was systematically reviewed, seeking the publications in eight journals from 2006 to 2016. Twenty-six studies were studied. Competitive production statistics and, consequently, small opportunities for action may be some of the reasons for the criticisms that make up much of the sport. What is easier to study than the pedagogical help of the teacher, the search for daily schooling and the presentation of tasks for the beginning of the dilemma do not present themselves in the teaching of sports in the School Physical Education.
\end{abstract}

Keywords: Education. Teaching. Collective sports. School physical education.

Resumen: El deporte es uno de los índices más frecuentes de la Educación Física escolar, siendo utilizado por muchos profesores con énfasis en la enseñanza de las habilidades motoras y gestuales. Sin embargo, los estudiantes reconocen su importancia en este sentido más allá de su práctica, priorizando los valores y principios educativos. El papel del artículo fue analizado como producción académica sobre la enseñanza

\footnotetext{
${ }^{1} \mathrm{O}$ presente trabalho não contou com apoio financeiro de nenhuma natureza para sua realização.

${ }^{2}$ Graduado e mestre em Educação Física, especialista em Treinamento Desportivo, professor do Estado da Bahia; foi coordenador do programa Segundo Tempo; é pesquisador do Laboratório de Estudos Culturais e Pedagógicos da Educ. Física; autor/coautor da coleção "Dialogando sobre o ensino da Educação Física". (gilfeitosa1@hotmail.com)

${ }^{3}$ Mestre e doutor em Educação Física. Realizou estágio de pós-doutorado em Ciências do Exercício e do Esporte. É professor da Universidade Federal do Vale do São Francisco. Coordena o projeto de extensão Dialogando sobre o Ensino da Educação Física e promove espaços de formação permanente para professores. (lightdiego@yahoo.com.br)
} 
de los deportes. Metodología general fue revisada sistemática, buscando las publicaciones en ocho revistas en el período de 2006 a 2016. Se estudiaron 26 estudios. Las estadísticas de producción competitiva y, por consiguiente, las pequeñas oportunidades de acción pueden ser algunos de los motivos de las críticas que hacen gran parte del deporte. Lo que es más fácil de ser estudiado que la ayuda pedagógica del profesor, la búsqueda del cotidiano de escolaridad y la presentación de tareas para el inicio del dilema no se presentan en la enseñanza de deportes en la Educación Física escolar.

Palabras-clave: Educación. Enseñanza. Deportes colectivos. Educación física escolar.

\section{Introdução}

Os conteúdos esportivos foram inseridos nas aulas de educação física do Brasil no início da década de 1950, com o Método Desportivo Generalizado. Entretanto, a sua ênfase como conteúdo quase que exclusivo se deu a partir da década de 1960 (COLETIVO DE AUTORES, 1992). Nesse período, o ensino dos esportes na escola foi elaborado a partir do Método Tradicional, cujo enfoque visava a desenvolver as técnicas esportivas, utilizando-se do modelo de alto rendimento com repetições de gestos técnicos.

Acompanhado do desenvolvimento tecnológico, o esporte se tornou um fenômeno de consumo, sendo utilizado como meio de promoção da saúde, instrumento de educação, lazer e formação de atletas. Todavia, foi introduzido na escola com característica excessiva de desempenho e exclusão dos menos habilidosos (MOURA, 2012; DARIDO, 2003). Para Paes (2001), a escola é um local em que deve haver a promoção e divulgação da cultura, portanto é um importante ambiente para o ensino do esporte.

A partir do final da década de 1970, uma série de autores começa a apontar a necessidade de modificar a forma como a educação física escolar vinha sendo estruturada (MOURA, 2012; CAPARROZ, 1997). Tomando como base as teorias críticas da educação, o principal aspecto defendido pelos autores era aproximar a educação física de um debate mais crítico, questionando o modelo de ensino que apenas reproduzia os moldes do esporte de rendimento.

Segundo Paes (2006, p.225) neste início do século XXI, a pedagogia do esporte apresentase como mediadora dessa discussão acadêmica e orientadora de novos procedimentos e intervenções profissionais, visando proporcionar à relação ensino e aprendizagem esportiva um embasamento cada vez mais científico.

Os esportes coletivos são um elemento cultural da humanidade, e a sua prática no contexto educacional carece de ressignificação para atender à função social da escola. Marco e Melo (2002) enfatizam que o esporte deve ser pautado pelos pressupostos metodológicos de uma pedagogia que respeite a faixa etária, as motivações e os interesses de seus praticantes. Para Moura (2012), a alta adesão nas atividades esportivas e competições é um fenômeno que movimenta toda a escola e é responsável por criar intensa sociabilidade e um sentimento de pertencimento.

Para Kunz (2001, p. 73), a escola se configura como um dos espaços de organização social onde as práticas esportivas acontecem, cabendo ao professor da educação física proporcionar, 
pela tematização do seu conteúdo específico, uma compreensão crítica das práticas esportivas, potencializando os sujeitos a estabelecer vínculos com o contexto sociocultural em que estão inseridos.

As discussões nesse sentido têm avançado na área de educação física escolar, e apesar de ainda distantes da realidade do professor que atua na escola (PAES, 1997), já é possível encontrar na literatura propostas metodológicas sobre modelos de ensino dos esportes coletivos educacionais. Essas propostas apresentam-se pautadas em atividades com situações-problema a partir de jogos (SADI, 2005; GRAÇA; MESQUITA, 2007) e métodos situacionais focando processos cognitivos (GRECO; BENDA, 1998; GRECO, 2001).

Apesar dos inúmeros avanços no debate sobre os esportes coletivos, Moura (2012) relata que tais produções pouco impactaram no cotidiano das escolas. Assim, o presente estudo tem por objetivo analisar as produções acadêmicas acerca do ensino dos esportivos coletivos na educação física escolar.

\section{Procedimentos metodológicos}

Utilizamos o método de revisão sistemática, que consiste em realizar uma análise das contribuições relevantes de produções acadêmicas no período de 2006 a 2016. Apesar dos intensos debates que ocorreram nos anos 1990 e 2000 sobre o esporte na educação física escolar, optamos por analisar os últimos dez anos por se tratar das publicações mais recentes. Não foram incluídos também no recorte os anos de 2017, destinado para coleta, intervenção e escrita, e 2018, ano da minha defesa de mestrado, períodos que provavelmente tenham estudos relevantes sobre a temática.

Segundo Sampaio e Mancini (2007), uma revisão sistemática é realizada a partir de cinco etapas: definição da pergunta; busca de evidências científicas; revisão e seleção dos conteúdos; análise da qualidade metodológica dos estudos e apresentação dos resultados. Como primeira fase, formulamos a pergunta que originou o presente estudo: Quais as contribuições acadêmicas da literatura nacional sobre o ensino dos esportivos coletivos na educação física escolar? Diante deste questionamento, passamos para a segunda fase, que foi a delimitação da busca nas revistas científicas.

As revistas selecionadas apresentam publicações na área da educação física e estavam classificadas nos extratos entre A1 e B2 no WebQualis. A busca dos artigos foi realizada por dois pesquisadores que, de forma independente, buscaram artigos sobre o tema nas seguintes revistas nacionais: Motriz, Movimento, Motrivivência, Revista Brasileira de Ciências do Esporte, Revista Brasileira de Ciência e Movimento, Revista Brasileira de Educação Física e Esporte, Revista da Educação Física - UEM e Revista Pensar a Prática. 
A terceira etapa da pesquisa foi a seleção dos artigos a serem analisados. Os critérios de inclusão foram: a) tematizar o ensino dos esportes coletivos na educação física escolar; c) ter sido publicado no arco temporal de 2006 a 2016; d) configurar-se como artigo original, artigo de revisão, ensaio ou relato de experiência. Utilizamos como descritores: ensino, educação e esportes coletivos. Através de uma leitura inicial do título e do resumo foram selecionados 85 artigos, sendo que 59 foram excluídos por não atenderem aos critérios de inclusão. Apresentamos na Tabela 1 a distribuição dos artigos encontrados entre os periódicos nacionais.

Tabela 1. Número inicial de artigos encontrados nos periódicos nacionais

\begin{tabular}{c|c|c|c}
\hline Descritores & \multicolumn{3}{|c}{ Ensino / Educação / Esportes coletivos } \\
\hline Periódicos Nacionais & Encontrados & Excluídos & Analisados \\
\hline RBCE & 04 & 0 & $\mathbf{0 4}$ \\
\hline RBCM & 03 & 01 & $\mathbf{0 2}$ \\
\hline RBEFE & 10 & 06 & $\mathbf{0 4}$ \\
\hline UEM & 07 & 05 & $\mathbf{0 2}$ \\
\hline PENSAR A PRÁTICA & 19 & 16 & $\mathbf{0 3}$ \\
\hline MOTRIVIVÊNCIA & 05 & 01 & $\mathbf{0 4}$ \\
\hline MOVIMENTO & 24 & 19 & $\mathbf{0 5}$ \\
\hline MOTRIZ & 13 & 11 & $\mathbf{0 2}$ \\
\hline Total & $\mathbf{8 5}$ & $\mathbf{5 9}$ & $\mathbf{2 6}$ \\
\hline
\end{tabular}

Fonte: próprios autores.

Ao final das buscas foram selecionados 26 artigos para o presente estudo. Na quarta fase, os artigos foram analisados com base em dois pontos: a metodologia utilizada pelos autores e as contribuições apresentadas para o ensino dos esportes coletivos na escola. Desta forma, a partir da técnica de análise de conteúdo (BARDIN, 2011), categorias foram criadas com base na leitura dos artigos, visando agrupar as semelhanças entre as pesquisas e as suas contribuições para o ensino dos esportes coletivos nas aulas de educação física escolar. Como quinta e última fase, a revisão sistemática apresenta os resultados obtidos por meio das análises dos estudos selecionados, presentes na próxima seção.

\section{Resultados e discussão}

Nesta seção apresentaremos os resultados da análise dos artigos. Construímos quatro 
categorias para melhor organizar os dados: a) Sistematização; b) Esporte educacional; c) Jogos e brincadeiras; d) Formação docente. Essas categorias foram construídas após a análise dos textos, como uma estratégia didática para facilitar a compreensão do debate.

\subsection{Sistematização}

Nessa categoria, encontram-se 16 artigos que relacionam as estratégias de organização do processo de ensino e aprendizagem dos esportes coletivos, além dos caminhos de tematização desse conteúdo. Desses artigos, quatro são revisões de literatura e 12 pesquisas de campo. O argumento central está relacionado com planejamento das aulas, estruturação de tarefas, organização e distribuição de conteúdos esportivos em unidades didáticas.

Diversos autores (MEDEIROS, 2007; SAWITZKI, 2008; PINA, 2010; PIMENTA; HONORATO, 2010; BARROSO; DARIDO, 2010; 2015) apontam a necessidade de problematizar e sistematizar o ensino dos esportes coletivos nas aulas. O processo pedagógico apresentado não só destacou o caráter seletivo, excludente, competitivo e mercadológico com que o esporte é revestido, como também a apropriação de elementos culturais para atribuir novos significados ao esporte (PINA, 2010). Nesse sentido, Pimenta e Honorato (2010) procuraram identificar e problematizar os conceitos do esporte, sistematizando-os com temas como sociedade, grandes empresas, mídia, violência, economia e a cultura brasileira.

A necessidade de planejamento e sistematização das ações desenvolvidas pelos professores na abordagem com os esportes coletivos é um consenso entre os artigos analisados nessa categoria (MEDEIROS, 2007; SAWITZKI, 2008; BARROSO; DARIDO, 2009; 2010; GALLATI et al., 2010; SOUZA JÚNIOR; DARIDO, 2010; PINA, 2010; PIMENTA; HONORATO, 2010; IMPOLCETO; DARIDO, 2011; CARLAN; KUNZ; FENSTERSEIFER, 2012; QUADROS; STEFANELLO; SAWITZKI, 2014; LUGUETTI et al. 2015; COSTA, NASCIMENTO; VIEIRA, 2016). No entanto, as formas de intervenção, as estratégias e os objetivos a serem alcançados durante esse processo são diversos, o que demonstra a falta de consenso da área no que se refere ao que ensinar e como ensinar. Além disso, o professor de educação física ainda restringe os conteúdos da disciplina aos jogos esportivos coletivos e apresenta poucos indícios de sistematização desse conteúdo na escola.

Costa, Nascimento e Vieira (2016) argumentam que os esportes de invasão podem ser planejados e sistematizados através de unidades didáticas. Quadros, Stefanello e Sawitzki, (2014) e Costa, Nascimento e Vieira, (2016) estruturaram suas aulas em uma lógica de melhoria dos domínios motor, cognitivo e afetivo, e as tarefas foram previamente esquematizadas por uma lógica de dificuldade crescente. Carlan, Kunz e Fensterseifer (2012) também procuraram organizar e planejar uma unidade didática em que o tema foi o futebol de sete. Entretanto, Carlan, Kunz e Fensterseifer (2012) se diferenciam de Costa, Nascimento e Vieira, (2016) e Quadros, 
Stefanello e Sawitzki, (2014) ao desenvolverem um processo de ensino e aprendizagem que busca superar o ensino do esporte pautado nos modelos de rendimento e da busca apenas por saberes corporais em detrimento de saberes sociais. Para eles, o futebol de sete foi além do que simplesmente ensinar a praticá-lo, pois utilizou como forma de sistematização e organização didático-metodológica o diagnóstico, a hierarquização de problemas, os objetivos de ensino e a sequência de temas. É importante ressaltar que as duas abordagens são exemplos de alternativas válidas contra a falta ou pouco planejamento e organização nas aulas de esportes coletivos.

Medeiros (2007), Sawitzki (2008), Barroso e Darido (2009) e Souza Júnior e Darido (2010) propõem uma sistematização através de jogos. Souza Júnior e Darido (2010) aprofundamse no tema "resgate de jogos" com o objetivo de apontar um conjunto de temas do conteúdo futebol que possam servir de subsídios para propostas de sistematização. Observaram os conhecimentos sistematizados a partir da utilização de textos, vivências, debates, pesquisas e outras estratégias de ensino dos esportes coletivos, buscando tornar as aprendizagens mais significativas. Foram apresentados nove temas que discutem aspectos relevantes do futebol, tais como suas relações com a arte, sua história e o contexto do futebol feminino. Por fim, o tema relativo aos jogos da cultura popular relacionados ao futebol foi aprofundado por meio do futebol de tampinhas e do futebol de botão, incluindo aprendizagens como a construção de regras, a interpretação de competições e a valorização da cultura popular.

Barroso e Darido (2009) constataram que as propostas dos autores da pedagogia do esporte têm forte tendência de ensino para utilização do jogo como recurso pedagógico. Para eles, o conhecimento deve ir além da aprendizagem de movimentos esportivos específicos. Para isso, deve haver a participação efetiva de todos, sem exclusão dos menos habilidosos, utilização de brincadeiras da cultura popular, realização de jogos em espaços menores e número reduzido de integrantes, além da realização de alterações em um jogo, aumentando gradativamente as dificuldades e desafios.

O livro didático é outra proposta de sistematização dos esportes coletivos sugerida por alguns autores (GALLATI et al., 2010; IMPOLCETO; DARIDO, 2011). Impolceto e Darido (2011) apontam que, para tecerem conclusões mais efetivas sobre a sistematização do voleibol, seria necessário elaborar um material didático. Indicaram como principais temas a história da modalidade, os fundamentos técnicos, os sistemas táticos, os jogos relacionados ao processo de ensino e aprendizagem, discussões sobre a relação desse esporte com a mídia e o vôlei sentado. No mesmo sentido, Gallati et al., (2010) concluem que uma formação aliada à utilização de um livro didático facilita o processo de ensino e aprendizagem dos esportes coletivos. Os autores propõem um livro didático organizado por módulos, considerando dois referenciais: um técnicotático e outro socioeducativo, buscando proporcionar a aprendizagem conceitual desse conteúdo. A utilização do livro didático pode auxiliar o professor no processo de ensino e aprendizagem, entretanto não deve ser a única fonte de pesquisa ao qual o professor recorra para planejar suas 
aulas, tampouco ser um material que venha para limitar as possibilidades de sistematização dos conteúdos.

Santos e Nista-Piccolo (2011) investigaram a visão dos professores sobre a aplicação do esporte em suas aulas, a partir de uma entrevista com dez professores, buscando compreender suas percepções, concepções e significados sobre a relação esporte/ educação física. Os resultados apresentados apontam o esporte relacionado às seguintes temáticas: esporte e educação; esporte e competição; esporte como um aspecto cultural; esporte na perspectiva das modalidades tradicionais; esporte e inclusão. Constatou-se uma carência de sistematização adequada de conhecimentos da educação física no Ensino Médio, o que, consequentemente, nos leva ao entendimento de que as ações governamentais, atuais propostas e currículos não modificaram em quase nada as aulas de educação física no Ensino Médio.

Entretanto, os esportes coletivos também podem ser abordados e sistematizados através de diferentes estratégias. Medeiros (2007) organiza uma sequência didática para o ensino do futebol através do "jogo dos seis quadrados", estimulando o protagonismo dos alunos no processo educativo, tendo autonomia para organizar suas equipes e elaborar regras, tornando-se uma estratégia pedagógica inovadora para uma ressignificação do esporte. No caso do voleibol, Barroso e Darido $(2010 ; 2015)$ apresentam uma proposta com base nas dimensões conceitual, procedimental e atitudinal, discutindo a relação entre a alteração do sistema de pontuação no voleibol de quadra e o tema transversal trabalho e consumo.

Os jogos escolares também são outro importante fator sobre os esportes coletivos. Sawitzki (2008) investigou se há coerência entre o planejamento e as práticas esportivas na escola. Entrevistou professores, diretores, coordenadores pedagógicos, alunos e a comunidade escolar. No estudo, constatou-se discordância entre o planejamento e a prática, bem como significativa influência do sistema esportivo. $\mathrm{O}$ autor propõe uma sistematização/organização alternativa desses eventos com uma maior participação da comunidade escolar. No entanto, para que isso seja possível é necessário que os esportes estejam articulados com o Projeto Político Pedagógico (PPP) da escola. Luguetti et al. (2015) analisaram o planejamento das práticas esportivas escolares e constataram que a ausência de um programa específico que as organizem e as sistematizem dificulta a inter-relação com outros componentes curriculares. Os professores apresentaram dificuldades de planejar e articular as ações relacionadas aos esportes coletivos na escola.

A elaboração de propostas de sistematização/organização dos conteúdos esportivos nas aulas de educação física pode auxiliar os professores no desenvolvimento de seus planejamentos, encontrando caminhos que possam adequar-se melhor às realidades e possibilidades de vivenciar esses conteúdos de forma significativa. De acordo com Antunes e Dantas (2010), na área da educação física escolar observa-se a ausência de propostas de organização curricular claramente definidas e testadas, situação que induz os docentes a elaborar por si próprios a sistematização 
dos conteúdos ou simplesmente não elaborar nenhuma proposta, dificultando o processo de ensino e aprendizagem.

É importante ressaltar que a sistematização dos conteúdos da educação física na escola ainda é uma lacuna na área, conforme observamos em diversas propostas, através da intervenção pedagógica, de experiências práticas, da iniciação esportiva, dos jogos, da utilização do livro didático ou sequências didáticas, de temas transversais e conceituais, etc.

\subsection{Esporte educacional}

Nesta categoria foram encontrados 12 artigos, sendo cinco revisões de literatura e oito pesquisas de campo. O foco está no debate sobre atividades esportivas voltadas para a construção e compreensão dos princípios e valores educacionais e culturais do esporte.

Reis et al. (2015) realizaram uma revisão sistemática sobre a educação física e ciências do esporte no período de 1998 a 2013, visando conhecer a discussão sobre o esporte educacional no Brasil. Os resultados apresentaram um desequilíbrio, com supremacia de estudos analíticos em detrimento de estudos propositivos. Há uma ausência de referenciais críticos e propositivos que auxiliem os professores sobre o esporte no contexto educacional. Rodrigues e Darido (2008) investigaram a concepção da técnica esportiva no ensino da educação física. Os autores apontam que é possível identificar novas finalidades quanto ao ensino das técnicas esportivas. Consideram o repertório cultural desses alunos, propondo que as aulas não se restrinjam à realização desses movimentos, mas também incluam o conhecimento do universo social, político, econômico e cultural das manifestações esportivas. Apontam que os gestos técnicos sejam um meio para alcançar outras finalidades educativas e não a única aprendizagem necessária.

Assim como Rodrigues e Darido (2008), Pina (2010) também se preocupou com a baixa interação social e as implicações pedagógicas dos esportes coletivos na escola. Além desses autores, Pimenta e Honorato (2010) se destacaram ao problematizar os esportes durante as aulas, pois através dessa intervenção seus alunos passaram a compreender o fenômeno esportivo de forma mais crítica e reflexiva. Nesse sentido, Pina (2010) buscou, a partir do conhecimento dos alunos sobre essa temática, estabelecer uma relação com a educação dos indivíduos e com a produção e circulação de mercadorias. O estudo não só destacou o caráter alienante com que o esporte é revestido, como também possibilitou a apropriação de elementos culturais para atribuir novos significados ao esporte, vivenciando as modalidades esportivas, de modo que a competição, a concorrência, o rendimento e a disputa sejam substituídos por valores que socializem, garantam a solidariedade e respeito, dentre outros.

Sawitzki (2008), Reverdito et al. (2008) e Frizzo (2013) analisaram as competições escolares destacando o caráter educativo do esporte. Sawitzki (2008) propõe uma organização alternativa para as práticas esportivas escolares fundamentada em princípios pedagógicos de 
formação humana e desenvolvimento da cidadania. Assim como Frizzo (2013), Sawitzki (2008) acredita na prática esportiva e nos jogos esportivos escolares como uma atividade capaz de contribuir para o desenvolvimento individual e social dos alunos. Entretanto, percebeu-se que os jogos escolares reforçam princípios e valores opostos àqueles idealizados pelo esporte educacional.

No mesmo sentido, Reverdito et al. (2008) refletem sobre o papel da competição e apresentam uma proposta com base na educabilidade do sujeito. Esta proposta foi sistematizada por princípios pedagógicos e metodológicos como totalidade, co-educação, cooperação, participação, autonomia, pluralidade cultural e valores sociais. Para esses autores (SAWITZKI, 2008; REVERDITO et al., 2008), o processo de ensino e aprendizagem pode ser realizado através do ambiente competitivo. Nesse caso, a vitória não deve ser tratada apenas como a única finalidade da competição.

As formas como são abordados os esportes coletivos também foram destaque em algumas pesquisas. Costa, Nascimento e Vieira (2016) destacam que o processo de intervenção pedagógica tendo como referência os princípios do Modelo Desenvolvimentista ${ }^{4}$ e Modelo de Educação Desportiva $^{5}$ contribuem para o desenvolvimento dos alunos. Já para Freire e Goda (2008), os professores podem usar oficinas de jogos na prática pedagógica, pois são capazes de produzir repercussões nas demais aprendizagens escolares, potencializando o pensamento, a motricidade, a sociabilidade, a moralidade, a afetividade etc. (FREIRE; GODA, 2008).

Medeiros (2007) aponta outra possibilidade de ressignificar o esporte apoiado numa concepção problematizadora que estimule a formação da cidadania crítica e emancipada, desenvolvendo a tolerância e aceitação das diferenças, respeito, satisfação, cooperação e companheirismo, tornando essa experiência mais significativa.

Também utilizando o futebol como veículo de aprendizagem, Faria (2014) apontou que se devem diversificar as formas de trabalhar um conteúdo, o que permite que um esporte tradicional como o futebol possa interagir de formas diferentes e que vão além do gesto técnico da modalidade. Isso envolve a incorporação de formas de agir, de movimentar o corpo, aspectos implícitos referentes à dimensão identitária, à prática coletiva, aos significados, às emoções, aos valores e a outros aspectos que possam surgir.

Os artigos dessa categoria enfatizam o caráter educacional com foco na formação e desenvolvimento de valores a partir do ensino do esporte. Podemos perceber que grande parte dos estudos realizou suas conclusões a partir de experiências fruto de práticas pedagógicas, o que

\footnotetext{
${ }^{4}$ O Modelo Desenvolvimentista para o ensino dos jogos esportivos foi elaborado na realidade norte-americana pela professora Judith Rink, nos anos de 1990, e divulgada em diversos países. Esse modelo preconiza uma progressão de tarefas tratadas didaticamente pelo professor.

${ }^{5}$ O Modelo de Educação Desportiva, por outro lado, é um modelo que preconiza o potencial educativo, buscando uma formação de alunos capazes de compreender o sentido do jogo, oportunizando a prática das modalidades esportivas e os aspectos afetivos evidenciados em cada prática.
} 
aproximam as proposições das práticas concretas dos professores. Todavia, observamos a falta de mais estudos propositivos, pois o debate sobre esporte educacional parece ter ficado mais no campo das ideias e menos no campo das ações, deixando de fornecer subsídios pedagógicos que possam auxiliar mais os professores no seu cotidiano escolar. Ainda assim, destacamos as propostas de Sawitzki (2008), Reverdito et al., (2008) e Frizzo (2013), que apresentaram uma alternativa para as competições escolares enfatizando o caráter educativo do esporte, e Costa, Nascimento e Vieira, (2016), Freire e Goda (2008) e Medeiros (2007), que utilizam intervenções pedagógicas para ensinar os esportes coletivos na escola.

\subsection{Jogos e brincadeiras}

Dos oito artigos presentes nessa categoria, temos duas revisões de literatura e seis pesquisas de campo. Todos os artigos presentes nessa categoria (MEDEIROS, 2007; FREIRE; GODA, 2008; SAWITZKI, 2008; BARROSO; DARIDO, 2009; SOUZA JÚNIOR; DARIDO, 2010; QUADROS; STEFANELLO; SAWITZKI, 2014; ANDRÉ; HASTIE; ARAÚJO, 2015) atribuem aos jogos e brincadeiras a otimização do processo de ensino e aprendizagem dos esportes coletivos.

Vários autores utilizaram a oficina de jogos como estratégia de ensino, sugerindo formas de intervenção, como criação de pequenos jogos, agrupando meninos e meninas; construção de acordos com os alunos; construção de material didático alternativo; iniciação esportiva através de jogos; aulas diversificadas para estimular a participação dos alunos; criação de jogos e regras pelos alunos etc. (MEDEIROS, 2007; FREIRE; GODA, 2008; QUADROS; STEFANELLO; SAWITZKI, 2014; ANDRÉ; HASTIE; ARAÚJO, 2015). Medeiros (2007) faz uma abordagem diferenciada do trabalho com o futebol, criando uma estratégia chamada de futebol de seis quadrados. Esta proposta possibilita aos alunos autonomia para organizar suas equipes, elaborar as regras, as punições e a dinâmica do jogo, estimulando os menos habilidosos a participar das aulas. Essa experiência pode proporcionar uma aprendizagem mais significativa e atribuir um novo olhar sobre a forma de abordar o futebol nas aulas.

Outros artigos também abordam o futebol como tema central (SOUZA JÚNIOR; DARIDO, 2010; FARIA, 2014). Para Souza Júnior e Darido (2010), o futebol pode ser vivenciado através de jogos que representem esse esporte, como o futebol de botão e o futebol de tampinha. É importante que as aulas representem não somente o esporte em seu formato original, mas também as variações presentes na cultura popular (SOUZA JÚNIOR; DARIDO, 2010). Já Faria (2014) aponta que o futebol precisa ser enfatizado a partir da realidade escolar local e explorado através de jogos e brincadeiras. A escassez de intervenções pedagógicas nas práticas futebolísticas não impede o diálogo entre diferentes maneiras de aprender no cotidiano escolar (FARIA, 2014), 
além de gerar motivação e prazer, favorecendo o ambiente da aprendizagem (BARROSO; DARIDO, 2009).

\subsection{Formação docente}

Nesta categoria foram selecionados seis artigos, sendo uma revisão de literatura e cinco pesquisas de campo. $\mathrm{O}$ foco dos artigos se concentra em analisar os dilemas da formação docente relacionados com o ensino dos esportes coletivos.

A formação inicial necessita ser avaliada e modificada para que o professor seja capaz de se relacionar com o ambiente educacional de forma mais segura e confiante (LUGUETTI et al., 2015). Os autores sugerem uma atenção às políticas de formação continuada e à organização curricular dos cursos de formação inicial. Apontam a necessidade de melhor articulação entre teoria e prática, além de uma aproximação mais adequada da realidade profissional. De acordo com os autores, diante do perfil dos professores investigados, foi possível observar também que tal fato possivelmente não ocorre, pois, em sua maioria, os docentes não usufruem de um programa de formação profissional adequado a essa finalidade. Além disso, os professores descrevem que o esporte ministrado está distante do projeto político pedagógico das escolas (LUGUETTI et al., 2015). Todavia, existem pesquisas que procuram auxiliar o professor na busca pela melhoria na sua prática docente, como é o caso da pesquisa de Barroso e Darido (2010). Os autores, juntamente com os professores, construíram, implementaram e avaliaram uma proposta de intervenção sobre o ensino do voleibol na escola. Essa assessoria permitiu aos professores evoluir em sua prática docente, além de oportunizar que os olhares sobre o trabalho do professor de educação física sejam percebidos positivamente na escola (BARROSO; DARIDO, 2010).

As pesquisas colaborativas ajudaram a identificar e intervir sobre as lacunas do processo de ensino e aprendizagem dos esportes coletivos na escola. Gonzáles e Borges (2015) realizaram uma pesquisa-ação com sete docentes. Os resultados apontam que existem possibilidades de mudança na atuação de professores que participam de experiências de pesquisa-ação, mas, pouco se sabe sobre quais os caminhos e dificuldades para ajudar os professores a mudarem sua forma de trabalho no que se refere ao ensino dos conteúdos procedimentais dos esportes.

Outro fator que pode auxiliar na superação dos obstáculos da formação inicial são os estágios. Ramos, Graça e Nascimento (2006) desenvolveram uma pesquisa com estagiários. Os dados foram obtidos a partir de observações, entrevistas e planejamentos construídos por três estudantes de licenciatura. Apesar das semelhanças verificadas quanto aos conteúdos e às metodologias empregadas na iniciação do basquetebol, identificaram-se propósitos pessoais distintos para o ensino, diretamente relacionados à experiência pessoal com a prática desportiva. Já Coutinho e Silva (2009) buscaram identificar os professores universitários em nove instituições de São Paulo. Os autores comprovaram que o método tradicional é destacadamente o mais 
conhecido entre os professores pesquisados; por outro lado, com relação aos métodos da linha crítica, houve um alto índice de desconhecimento desses métodos. A formação inicial e continuada do professor de educação física necessita maior destaque nos programas de valorização do docente. O planejamento de ações voltadas para a formação docente é de vital importância para a melhoria do processo de ensino e aprendizagem dos esportes coletivos na escola. Caso contrário, as aulas de educação física apenas reproduzirão o esporte de rendimento e as práticas tradicionais.

\section{Considerações finais}

O presente estudo analisou as produções acadêmicas sobre o ensino dos esportes coletivos na educação física escolar no período entre 2006 e 2016. Utilizamos a revisão sistemática com propósito de encontrar na literatura elementos que indicassem as contribuições acadêmicas acerca do ensino dos esportes coletivos para a educação física escolar.

Ao analisarmos os artigos sobre o ensino dos esportes coletivos, observamos que a sistematização, o esporte educacional, os jogos e brincadeiras e a formação docente surgem como principais temas discutidos.

Podemos observar que a sistematização dos conteúdos da educação física na escola ainda é uma lacuna na área. Ainda há uma ideia de sistematização relacionada apenas com a aprendizagem do esporte. Todavia, coexistem propostas de sistematização de temas transversais, atividades diferenciadas, dimensões de conteúdos e utilização de livros didáticos.

Os artigos que tratam do esporte educacional trazem como foco a formação e desenvolvimento de princípios e valores a partir do ensino do esporte, tendo como premissa a inclusão e a formação esportiva e cidadã. Porém, esse discurso precisa sair do campo das ideias, tornando-se, de fato, uma intervenção no campo prático, uma vez que já existem estudos que enfatizam a pedagogia do esporte como metodologia capaz de superar a hegemonia da abordagem tradicional de ensino dos esportes, buscando aproximar a relação entre teoria e prática.

Os jogos e brincadeiras destacam-se pelo potencial do componente lúdico na aprendizagem, capazes de produzir repercussões nas demais aprendizagens, e são sugeridos por diversos autores como uma ferramenta relevante para o ensino dos esportes. Já a formação docente sinalizou uma carência de estudos que abordem o contexto da formação inicial e continuada do professor de educação física, principalmente no trato com o ensino do esporte. Nesse sentido, é fundamental aumentar o número de pesquisas com os professores na escola para que a formação dialogue com os seus dilemas reais.

É importante salientar que, apesar de o esporte ser o conteúdo hegemônico das aulas de educação física, encontramos poucos estudos propositivos na literatura acerca do ensino do esporte na escola. Logo, são necessários mais estudos, principalmente no contexto escolar. 
Esperamos que este artigo possa servir de auxílio e orientação para outros estudos e investigações sobre o ensino do esporte na escola.

\section{Referências}

ANDRÉ, Mauro H; HASTIE, Peter; ARAÚJO, Rui F. O desenvolvimento da compreensão holística do jogo por meio da criação do jogo. Revista Brasileira de Ciências do Esporte, v. 37, n. 4, p. 323-332, 2015.

ANTUNES, Fábia H. C; DANTAS, Luiz. Sistematização do conhecimento declarativo em educação física escolar de $5^{\mathrm{a}}$ a $8^{\mathrm{a}}$ séries do ensino fundamental. Revista Brasileira de Educação Física e Esporte; 24(2): 205-221. 2010.

BARDIN, Laurence. Análise de conteúdo. 3. reimp. Lisboa: Edições, v. 70, 2011.

BARROSO, André L. R; DARIDO, Suraya C. A pedagogia do esporte e as dimensões dos conteúdos: conceitual, procedimental e atitudinal. Revista da Educação Física/UEM, v. 20, n. 2, p. 281-289, 2009.

BARROSO, André L. Voleibol escolar: uma proposta de ensino nas dimensões conceitual, procedimental e atitudinal do conteúdo. Revista Brasileira de Educação Física e Esporte, v. 24, n. 2, p. 179-194, 2010.

O sistema de pontuação no voleibol de quadra e o tema transversal trabalho e consumo: possibilidades pedagógicas. Pensar a Prática, v. 18, n. 1, mar. 2015.

CAPARROZ, Francisco E. Entre a educação física da escola e a educação física na escola. Campinas: Autores associados; 1997.

CAPARROZ, Francisco E; BRACHT, Valter. "O tempo e o lugar de uma didática da educação física." Revista Brasileira de Ciências do Esporte 28.2 (2007).

CARLAN, Paulo; KUNZ, Elenor; FENSTERSEIFER, Paulo E. O esporte como conteúdo da Educação Física escolar: estudo de caso de uma prática pedagógica "inovadora". Movimento, v. 18, n. 4, p. 55-75, 2012.

COLETIVO DE AUTORES. Metodologia, do ensino de educação física. São Paulo: Cortez, 1992.

COSTA, Luciane C. A; NASCIMENTO, Juarez V; VIEIRA, Lenamar F. Ensino dos esportes coletivos de invasão no ambiente escolar: da teoria à prática na perspectiva de um modelo híbrido. Revista da Educação Física/UEM, v. 27, n. 1, 2016.

COUTINHO, Nilton F; SILVA, Sheila A. P. S. Conhecimento e aplicação de métodos de ensino para os jogos esportivos coletivos na formação profissional em educação física. Movimento, v. 15, n. 1, p. 117-144, 2009.

DARIDO, Suraya C. Educação física na escola: questões e reflexões. Rio de Janeiro: Guanabara koogan, 2003.

FARIA, Eliene L. Quando "rola a bola": reflexões sobre as práticas futebolísticas e a forma escolar nas aulas de educação física. Revista Brasileira de Ciências do Esporte, v. 36, n. 2, 2014. FREIRE, João B; GODA, Ciro. Fabricando: as oficinas do jogo como proposta educacional nas séries iniciais do ensino fundamental. Movimento, v. 14, n. 1, p. 111-134, 2008.

FRIZZO, Giovanni. Os jogos escolares como mecanismos de manutenção e eliminação: uma crítica à lógica esportiva na escola. Movimento, v. 19, n. 4, p. 163-180, 2013.

GALATTI, Larissa R. et al. Pedagogia do Esporte: livro didático aplicado aos Jogos Esportivos Coletivos. Motriz, 2010.

GONZÁLEZ, Fernando J; BORGES, Robson M. Diálogos sobre o ensino dos esportes na Educação Física escolar: uma pesquisa-ação na formação continuada. Motrivivência, v. 27, n. 45, p. 172-188, 2015. 
GONZÁLEZ, Fernando J; FENSTERSEIFER, Paulo E. Educação Física e cultura escolar: critérios para a identificação do abandono docente. Congresso de Educación Física "Repensar la Educación Física”. IPEF. Córdoba, Septiembre. 2006.

GRAÇA, Amândio; MESQUITA, Isabel. A investigação sobre os modelos de ensino dos jogos desportivos. Revista portuguesa de ciências do desporto, v. 7, n. 3, p. 401-421, 2007.

GRECO, Pablo J. Métodos de ensino-aprendizagem-treinamento nos jogos esportivos coletivos. Temas atuais em educação física e esportes, p. 48-72, 2001.

GRECO, Pablo J; BENDA, Rodolfo N. Iniciação esportiva universal. Belo Horizonte: UFMG, 1998.

IMPOLCETTO, Fernanda M; DARIDO, Suraya C. Sistematização dos conteúdos do voleibol: possibilidades para a Educação Física escolar. Revista Brasileira de Ciência e Movimento, v. 19, n. 2, p. 90-100, 2011.

KUNZ, Elenor. Transformação didático-pedagógica do esporte. Ijuí, RS: Ed. da Unijuí, 2001. LUGUETTI, Carla N. et al. O planejamento das práticas esportivas escolares no ensino fundamental na cidade de Santos. Revista Brasileira de Ciências do Esporte, v. 37, n. 4, p. 314322, 2015.

MARCO, Ademir de; MELO, José P. Desenvolvimento Humano, educação e esporte. In: MOREIRA, W.W; SIMÕES, R. (Org.). Esporte como fator de qualidade de vida. 2 . ed. Piracicaba: Unimep, 2002.

MEDEIROS, Francisco E. O futebol de seis “quadrados" nas aulas de educação física: uma experiência de ensino com princípios didáticos da abordagem crítico-emancipatória. Revista Brasileira de Ciências do Esporte, v. 28, n. 2, 2007.

MOURA, Diego L. Cultura e Educação Física Escolar: da teoria à prática. São Paulo: Phorte, 2012.

PAES, Roberto R. Aprendizagem e competição precoce: o caso do basquetebol. 3. ed. Campinas: Ed. da Unicamp, 1997.

Educação física escolar. Editora da ULBRA, 2001.

Pedagogia do Esporte: Especialização Esportiva Precoce. In: TANI, GO; BENTO, Jorge Olímpio; PETERSEN, Ricardo Demétrio de Souza. Pedagogia do Desporto. Rio de Janeiro: Guanabara Koogan, 2006. p. 219226.

PIMENTA, Thiago; HONORATO, Tony. Esporte moderno e mediação pedagógica nas aulas de educação física. Revista Brasileira de Educação Física e Esporte, São Paulo, v. 24, n. 4, p. 493-505, 2010.

PINA, Leonardo D. Pedagogia histórico-crítica e transmissão do conhecimento sistematizado sobre o esporte na educação física. Motrivivência, v. 20, n. 31, p. 115-131, 2010.

QUADROS, Roberta B; STEFANELLO, Daniela; SAWITZKI, Rosalvo L. A prática da cultura esportiva nas aulas de Educação Física. Motrivivência, v. 26, n. 42, p. 238-349, 2014.

RAMOS, Valmor; GRAÇA, Amândio B. S; NASCIMENTO, Juarez V. A representação do ensino do basquetebol em contexto escolar: estudos de casos na formação inicial em educação física. Revista Brasileira de Educação Física e Esporte, v. 20, n. 1, p. 37-49, 2006.

REIS, Nadson S. et al. O esporte educacional como tema da produção de conhecimento no periodismo científico brasileiro: uma revisão sistemática. Goiânia: Pensar a Prática, v. 18, n. 3, 2015.

REVERDITO, Riller S. et al. Competições escolares: reflexão e ação em pedagogia do esporte para fazer a diferença na escola. Goiânia: Pensar a prática, v. 11, n. 1, p. 37-45, 2008.

RODRIGUES, Heitor A; DARIDO, Suraya C. A técnica esportiva em aulas de educação física: um olhar sobre as tendências socioculturais. Movimento, v. 14, n. 2, p. 137-154, 2008.

SADI, Renato S. Educação Física, trabalho e profissão. Komedi, 2005. 
SAMPAIO, Rosana F; MANCINI, Marisa C. Systematic review studies: a guide for careful synthesis of the scientific evidence. Brazilian Journal of Physical Therapy, v. 11, n. 1, p. 83-89, 2007.

SANTOS, Marco A. G. N; NISTA-PICCOLO, Vilma L. O esporte e o ensino médio: a visão dos professores de educação física da rede pública. Revista Brasileira de Educação Física e Esporte, v. 25, n. 1, p. 65-78, 2011.

SAWITZKI, Rosalvo L. Esporte Escolar: aspectos pedagógicos e de formação humana. Motrivivência, v. 20, n. 31, p. 132-142, 2008.

SOUZA JÚNIOR, Osmar M; DARIDO, Suraya C. Refletindo sobre a tematização do futebol na Educação Física escolar. Motriz: Revista de Educação Física, p. 920-930, 2010.

Artigo recebido em: 28/06/2019

Artigo aceito para publicação em: 09/09/2019 